\title{
Spinal cord transection for definitive untethering of repetitive tethered cord
}

\author{
Jeffrey P. Blount, M.D., ${ }^{1}$ R. Shane Tubbs, M.S., P.A.-C., Ph.D., ${ }^{1,2}$ \\ John C. Wellons III, M.D., ${ }^{1}$ Leslie ACaKPo-Satchivi, M.D., Ph.D., ${ }^{1}$ \\ DAVID Bauer, M.D., ${ }^{1}$ AND W. JERry OAKES, M.D. ${ }^{1}$
}

${ }^{I}$ Section of Pediatric Neurosurgery and ${ }^{2}$ Department of Cell Biology, University of Alabama at Birmingham and Children's Hospital, Birmingham, Alabama

\begin{abstract}
$\checkmark$ In certain highly selected circumstances, division of a distally nonfunctional or dysfunctional cord can be a means of definitive untethering that spares and protects more rostral neurological function and results in definitive untethering. The authors reviewed their institutional experience with such cases and evaluated the limited literature. Based on their experience, treatment can be effective in carefully selected patients who undergo spinal cord transection, and the rate of repetitive tethered spinal cord can be decreased. Although uncommon, spinal cord transection appears to be an effective therapy in carefully selected patents with symptoms of repetitive cord tethering.
\end{abstract} (DOI: 10.3171/FOC-07/08/E12)

KEY WORDS • pediatric neurosurgery - spinal dysraphism • tethered cord

$\mathrm{F}$ EW NOTIONS ARE as inherently esthetically displeasing to the neurosurgeon as deliberately dividing the human spinal cord. Nonetheless, in certain highly selected cases, division of a distally nonfunctional or dysfunctional cord can be a means of definitive untethering that spares and protects more rostral neurological function and results in definitive untethering. In our experience, the most common such circumstance involves the symptomatic repetitively tethered cord in patients with paraplegia and spina bifida.

\section{Spinal Cord Transection}

\section{Tethered Cord and Transection}

Tethering of the spinal cord at the site of myelomeningocele closure or lipomyelomeningocele removal is thought to occur in virtually all patients who have undergone such procedures. ${ }^{5}$ Approximately 30 to $50 \%$ of these patients will develop symptoms, most commonly consisting of progressively severe back pain, scoliosis, and deterioration in distal neurological function (sphincter control, movement, and sensation).1,4,12,17 Gait impairment and joint deformity may follow. ${ }^{7}$ Central to the current concept of TCS is the gradual longitudinal traction that occurs due to the child's normal growth in the setting of a spinal cord

Abbreviations used in this paper: $\mathrm{CSF}=$ cerebrospinal fluid; TCS $=$ tethered cord syndrome. that is tethered at its caudal extent. ${ }^{18}$ Surgical untethering has been consistently shown to be helpful in relieving pain and arresting the rate of neurological decline in cases of symptomatic TCS. ${ }^{5,6,11}$ One of the challenges of surgical treatment has been the prevention of recurrent tethered cord. ${ }^{2,19}$ Although deliberate microsurgical untethering results in liberation of the cord, the newly released neural elements remain in immediate proximity to the dura mater or the dural graft used in closure. Natural healing and scar formation allow the tissue to reattach, and this may ultimately lead to symptoms of recurrent tethering. A number of technical adjuncts have been proposed to reduce the likelihood of recurrence (including patch grafts for dural closure, maximizing the extent of pial surface adjacent to the dura, placing stay sutures across the canal to keep the cord positioned anteriorly, and prone postoperative positioning), but none has been proven over time and at multiple centers to be effective in preventing recurrent TCS. . $^{8,19}$ It is estimated that approximately 25 to $30 \%$ of patients undergoing surgical release of a tethered cord may present later with signs and symptoms of recurrent tethered cord. Risk factors for recurrent tethering include a young age and a large placode at presentation with initial TCS. Symptoms of recurrent TCS are the same as those at the initial presentation. ${ }^{3,18}$ Pain is predominant and progressive. Axial spine pain is common in patients with spina bifida but is usually relatively stable, shows little progression over time, is relatively mild, and is well accommodated by patients. Other sources of progressive and more severe 
axial spine pain (for example, instability with spondylolisthesis) are uncommon but need to be ruled out.

There are multiple advantages to transecting the spinal cord when treating recurrent TCS., ${ }^{3,12}$ The spinal cord is transected at the most distal normal segment above the placode. As such, the approach is through normal tissue, which allows, later, for an anatomical watertight closure. Furthermore, the cord can be transected where it lies freely within a sufficiently large canal, at which point contact between fresh surgical edges and the dura is minimal and intermittent. This is in sharp contrast to a reexploration of a myelomeningocele closure, in which a large placode completely fills the canal and often touches the soft-tissue planes that are drawn up to close it. At the site of surgical transection, the normal circumferential pial covering of the cord is left intact. This prevents further retethering.

The rationale and justification for so extreme an intervention as spinal cord transection derive from the awareness that TCS threatens proximal and distal neurological capability. In practical terms, this justifies complete sacrifice of already profoundly impaired lower-extremity and sphincter function to preserve upper-extremity and bulbar function. The presence of a syrinx is one important mechanism by which proximal spinal cord function may be compromised; however, deterioration in upper-extremity function may occur in patients with progressive recurrent tethered cord in the absence of a syrinx. ${ }^{10}$ We advocate comprehensive, whole-spine magnetic resonance imaging evaluation in all patients being considered for spinal cord sectioning. If a syrinx is demonstrated, we require that adequate shunt function be demonstrated intraoperatively (that is, by surgical exploration and revision of the shunt) before considering a patient a candidate for spinal cord transection. If poor shunt function is found at the time of shunt exploration, shunt revision is performed and repeated imaging is conducted in 6 months. Reduction in syringomyelia and stabilization of progressive symptoms eliminate the patient's candidacy for cord transection. If a syrinx remains present and symptoms are progressive, we evaluate lower-extremity function in light of the patient's possible candidacy for cord transection.

IT IS ESSENTIAL that only patients with extremely impaired distal neurological function (lower-extremity and sphincter function) be considered for this intervention. Although we have not insisted that dysfunction be absolutely complete (that is, complete absence of any neurological function below the level of the placode), we have required that functionally complete distal paraplegia be documented. As such, patients with a nonfunctionally relevant degree of motion in the proximal lower extremities are candidates for cord transection if recurrent symptomatic cord tethering can be clinically demonstrated. We have not disqualified any patient on the basis of sensory findings because it has been our experience clinically that sensory performance closely mirrors motor capacity, and we only offer cord transection to patients whom we believe are at significant risk of global decline and progressive severe pain due to recurrent tethering and its consequences (in other words, sensory insult resulting from spinal cord transection is less serious than natural history of the disease). We do emphasize to the patient and fami- ly that the surgery will diminish sensory capacity and that risks for deafferentation-related complications, such as skin breakdown and pressure sores, may be significantly greater.

The informed consent discussion must be carefully conducted. We emphasize to families and patients the seriousness of recurrent TCS and the difficulty of treating and preventing it. We review alternative options, including repeated microsurgical exploration of the previous closure site, but indicate our concerns over the potential for the following: 1) the impaired ability to completely untether the cord and the continued risk for deterioration due to the tethered cord, and 2) the possibility of causing an injury as serious as transection due to the robust scar usually encountered and the already compromised neural tissue present. We recommend spinal cord transection for appropriately selected patients. Additionally, we directly state that we will be sectioning the distal end of the spinal cord just above the previous placode closure and that the procedure will cause irreversible spinal injury beyond that level. We also emphasize, however, that distal function has to be functionally absent to allow the patient to be a candidate and that the procedure has an excellent likelihood of resulting in complete untethering, with nearly absent risk of retethering. We further review the relatively low risk of infection or CSF leak that may require additional surgery.

\section{Surgical Technique}

The preoperative magnetic resonance imaging studies are scrutinized to determine the last normal imaging-documented level. In a latex-free environment, general anesthesia is induced and the patient is positioned prone with all pressure points carefully padded. A bladder catheter and several large-bore intravenous catheters are placed. Intravenous antibiotics $(25 \mathrm{mg} / \mathrm{kg}$ cefazolin) and steroids (dexamethasone $0.1-0.3 \mathrm{mg} / \mathrm{kg}$ [usually $2-4 \mathrm{mg}$ ]) are given. The rationale for using steroids is that the tethered cord is already mildly and chronically traumatized and may have little or no reserve for manipulation. An arterial line is not usually necessary but is occasionally used at the discretion of the anesthesiologist. A midline posterior incision is planned; this usually incorporates the proximal end of the previous closure. Lateral plain lumbar radiography or $\mathrm{C}$-arm radiography is performed to confirm the most caudal normal level, and the incision and approach corridor are planned. A routine midline approach, such as that for any laminectomy, is made. Because the involved level is by definition normal, the anatomy is not significantly distorted. The spinous process and lamina are removed, and the operating microscope is brought into the field. The dura mater is opened and retracted with sutures, which allows visualization of the cord. The cord is often displaced posteriorly and may not show pulsatility typical of normal cord. The pia mater is gently scored with the bipolar cautery and then opened sharply with microscissors. We emphasize the importance of judicious and careful use of the bipolar cautery to avoid or minimize any heat-induced traction of an already compromised spinal cord. We coagulate a few millimeters at a time only and keep the bipolar tips close together and perpendicular with the long axis of the cord. Once the pia mater is opened, the cord is 
divided using standard subpial dissection techniques. It is common for the cord to retract several millimeters on completion of the transection. All blood products are irrigated away and the dura, muscle, fascia, and skin are closed in routine fashion.

\section{Results of Surgical Series}

As outlined in a previous publication, we have performed spinal cord transection in 14 patients with recurrent tethered cord. ${ }^{3}$ Thirteen patients had suffered multiple episodes of recurrent tethering. One patient presented with a CSF leak and large pressure sores that eroded the placode closure. Each operation was performed without difficulty or complication using the aforementioned techniques. Each patient exhibited no further evidence of symptomatic tethering, but one child has now returned with recurrence of a syrinx. At initial surgical exploration we observed shunt dysfunction, and we are awaiting follow-up imaging results to determine whether the syrinx has shrunken or been resolved. If there is no improvement, we will reexplore and secure the opening of the central canal out to the dural edges to ensure adequate communication between the syrinx/central canal and the subarachnoid space.

We have observed only one case in which spinal cord transection did not lead to prompt improvement in a tethered cord-induced syrinx. In this case-a 13-year-old girl-we noted very dense thickened arachnoiditis immediately upon opening the dura, obscuring the normal anatomy. Despite apparent success in sectioning the cord uneventfully, the cord did not retract or move after we divided it. We hypothesize that a great extent of the cord was longitudinally tethered such that it was not liberated even by an intervention as dramatic as division of the cord.

\section{Discussion}

Relatively little has been written about iatrogenic spinal cord transection. Winston and colleagues ${ }^{17}$ have reported a single case report of a child who underwent cord transection for recurrent tethered cord who died shortly thereafter of presumed shunt malfunction. ${ }^{10,12-16}$ These authors cautioned that a functioning ventriculoperitoneal shunt is essential, believing that even a nonfunctioning spinal cord could convey CSF to the spinal subarachnoid space. Phillips and Jane ${ }^{9}$ have reported conducting this stimulation to determine the site where the placode becomes autonomous. In other words, if stimulation of the cord above the placode produces no response in the legs, then at a certain point in the placode there are exaggerated responses in the legs and this is where the transection should be conducted. Each of our patients had a ventriculoperitoneal shunt in place at the time of surgery, and in each case shunt function had proven to be adequate. Tibbs et al., ${ }^{13-16}$ provided a series of observations on iatrogenic cervical cord transection. Initially a $45 \%$ increase in mean arterial pressure was observed and followed by a $34 \%$ increase in systemic vascular resistance in a dog model of spinal cord transection. Some concomitant bradyarrhythmias were also observed. Mean arterial blood pressure also fell, but cerebral perfusion pressure was preserved by autoregulation if mean arterial blood pressure remained greater than 60 torr.
We observed no evidence of autonomic or hemodynamic change of significance in our 14 patients who underwent spinal cord transection.

\section{Conclusions}

Elective transection of the spinal cord at the last distal segment preceding the placode is an effective and apparently safe treatment for recurrent symptomatic cord tethering. Only patients with functionally complete spinal cord dysfunction who have clinical evidence of progressive symptomatic TCS and evidence of a functional shunt are candidates for spinal cord transection. Although we did not encounter any clinical problems following the procedure, evaluation of the literature suggests that there is at least the potential for hemodynamic and autonomic instability and decline due to symptomatic hydrocephalus. As such, it is essential that all patients be closely observed in the postoperative period for any signs of hemodynamic instability or shunt failure.

\section{References}

1. Balasubramaniam C, Laurent JP, McCluggage C, Oshman D, Cheek WR: Tethered-cord syndrome after repair of meningomyelocele. Childs Nerv Syst 6:208-211, 1990

2. Barolat G, Schaefer D, Zeme S: Recurrent spinal cord tethering by sacral nerve root following lipomyelomeningocele surgery. Case report. J Neurosurg 75:143-145, 1991

3. Blount JP, Tubbs RS, Okor M, Tyler-Kabara EC, Wellons JC, Grabb PA, et al: Supraplacode spinal cord transection in paraplegic patients with myelodysplasia and repetitive symptomatic tethered spinal cord. J Neurosurg 103 (1 Suppl):36-39, 2005

4. Bowman RM, McLone DG, Grant JA, Tomita T, Ito JA: Spina bifida outcome: a 25-year prospective. Pediatr Neurosurg 34: 114-120, 2001

5. Hudgins RJ, Gilreath CL: Tethered spinal cord following repair of myelomeningocele. Neurosurg Focus 16(2):E7, 2004

6. Kang JK, Lee KS, Jeun SS, Lee IW, Kim MC: Role of surgery for maintaining urological function and prevention of retethering in the treatment of lipomeningomyelocele: experience recorded in 75 lipomeningomyelocele patients. Childs Nerv Syst 19:23-29, 2003

7. McLone DG, Herman JM, Gabrieli AP, Dias L: Tethered cord as a cause of scoliosis in children with a myelomeningocele. Pediatr Neurosurg 16:8-13, 1990

8. Michelson DJ, Ashwal S: Tethered cord syndrome in childhood: diagnostic features and relationship to congenital anomalies. Neurol Res 26:745-753, 2004

9. Phillips LH II, Jane JA: Electrophysiologic monitoring during tethered spinal cord release. Clin Neurosurg 43:163-174, 1996

10. Ragnarsson TS, Durward QJ, Nordgren RE: Spinal cord tethering after traumatic paraplegia with late neurological deterioration. J Neurosurg 64:397-401, 1986

11. Schoenmakers MAGC, Gooskens RHJM, Gulmans VAM, Hanio PW, Vandertop WP, Uiterwaal CSPM, et al: Long-term outcome of neurosurgical untethering on neurosegmental motor and ambulation levels. Dev Med Child Neurol 45:551-555, 2003

12. Shurtleff DB, Duguay S, Duguay G, Moskowitz D, Weinberger E, Roberts T, et al: Epidemiology of tethered cord with meningomyelocele. Eur J Pediatr Surg 7 (1 Suppl):7-11, 1997

13. Tibbs PA, Young B, McAllister RG Jr, Brooks WH, Tackett L: Studies of experimental cervical spinal cord transection. Part I: Hemodynamic changes after acute cervical spinal cord transection. J Neurosurg 49:558-562, 1978 


\section{J. P. Blount et al.}

14. Tibbs PA, Young B, McAllister RG Jr, Todd EP: Studies of experimental cervical spinal cord transection. Part III: Effects of acute cervical spinal cord transection on cerebral blood flow. J Neurosurg 50:633-638, 1979

15. Tibbs PA, Young B, Todd EP, McAllister RG, Hubbard S: Studies of experimental cervical spinal cord transection. Part IV: Effects of cervical spinal cord transection on myocardial blood flow in anesthetized dogs. J Neurosurg 52:197-202, 1980

16. Tibbs PA, Young B, Ziegler MG, McAllister RG: Studies of experimental cervical spinal cord transection. Part II: Plasma norepinephrine levels after acute cervical spinal cord transection. J Neurosurg 50:629-632, 1979

17. Winston K, Hall J, Johnson D, Micheli L: Acute elevation of intracranial pressure following transection of non-functional spinal cord. Clin Orthop Relat Res 128:41-44, 1977

18. Yamada S, Knerium DS, Mandybur GM, Schultz RL, Yamada BS: Pathophysiology of tethered cord syndrome and other complex factors. Neurol Res 26:722-726, 2004

19. Zide B, Constantini S, Epstein FJ: Prevention of recurrent tethered spinal cord. Pediatr Neurosurg 22:111-114, 1995

Manuscript submitted May 30, 2007.

Accepted June 21, 2007.

Address reprint requests to: R. Shane Tubbs, Ph.D., Pediatric Neurosurgery, Children's Hospital, 1600 7th Avenue South, ACC 400, Birmingham, Alabama 35233. email: rstubbs@uab.edu. 